\title{
Breaking News on the Authenticity of Olive Oils by Means of Molecular Markers
}

\author{
Innocenzo Muzzalupo* \\ Council for Agricultural Research and Economics, Research Centre for Olive, Italy
}

*Corresponding author: Innocenzo Muzzalupo, Council for Agricultural Research and Economics, Research Centre for Olive, Citrus and Tree Fruit (CREA-OFA), C.da Li Rocchi-Vermicelli, 87036 Rende (CS), Italy

Submission: July 09, 2017; Published: December 04, 2017

\begin{abstract}
The labelling of food products is essential to inform the consumers about the products that they are buying. The EECn ${ }^{\circ} 2081 / 1992$, has defined the relative contribution of specific cultivars for every commercial oil designation. For this reason, the identification of olive genotypes used for the production of Extra Virgin Olive Oil (EVOO) is essential for the final characteristics of designation oils as the Protected Designation of Origin (POD), Registered Designation of Origin (RDO), and Protected Geographical Indication status (PGI).

The aim of this mini-review is to point out the latest innovations on the main issues of the composition and the authentication of EVOOs by means of microsatellites markers. The comparing between the molecular SSR profiles and the same loci present in an online molecular databases, allows establishing the origin olive varieties and the respect for the disciplinary of production (POD, RDO, PGI, etc.,). In Italy, some laboratories already work on this certification and by computerizing the molecular profiles obtained from the EVOO, can process an "identity card" that can be inserted into a barcode or QR code or microchips on the labels or bottle caps and it can be consulted by producers, consumers, and controllers via a mobile phone.
\end{abstract}

Keywords: Food traceability; Food genomics; Microsatellites; Virgin olive oils

\section{Introduction}

Food genomics relies on the hypothesis that remnant DNA in a food matrix can be recovered to serve as an analyte in food authenticity analyses [1]. As recent reviewed this hypothesis has led to the successful development of DNA-based food authenticity tests $[2,3]$.

The labelling of food products is essential to inform the consumers about the products that they are buying. The European Union (EU) harmonised rules on food labelling, presentation and advertising aim to protect consumers and facilitate trade inside and outside Europe.

Recently, an initiative of the European Parliament has identified a number of foods such as olive oil, fish, honey, dairy products and meat as being the target of fraudulent activities. This initiative calls for the development of technologies and methods to detect food fraud [3].

At international level, olive oil quality is regulated by the International Olive Council(IOC) trade standard, Codex Alimentarius at EU level by Regulation (EEC) $n^{\circ} 2568 / 91$, establishing a list of chemical and organoleptic characteristics, as well as methods for their analysis. This list and the methods are regularly updated to reflect scientific progresses. Despite this regulation, detection methods are lacking for certain fraudulent manipulations [4].

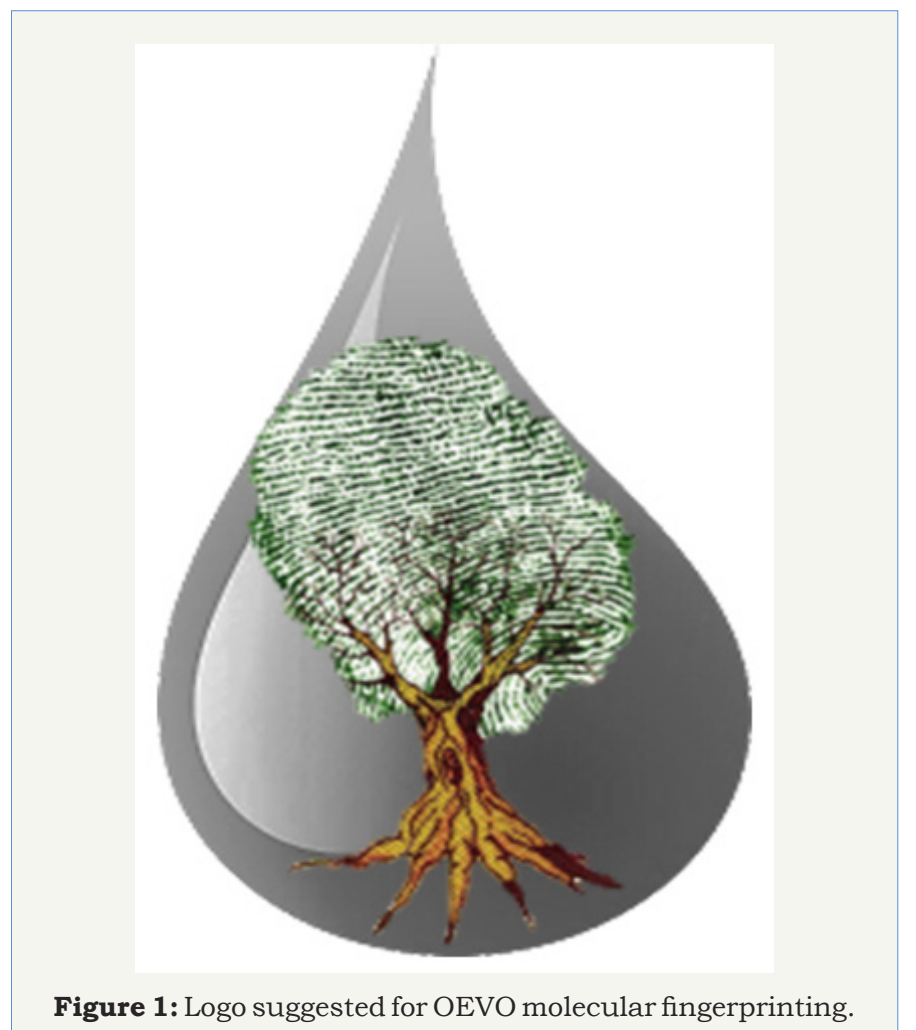

Figure 1: Logo suggested for OEVO molecular fingerprinting. 
Different olive varieties are associated with different environmental living conditions, and are characterized by different chemical patterns, resulting in different organoleptic properties [5]. Some olive varieties are identified as being of higher quality because they derive from particular ancient olive cultivars and from well-defined geographical areas and generally are legally protected. Indeed, the aims of the Protected Designation of Origin (PDO), the Registered Designation of Origin (RDO) or the Protected Geographical Indication (PGI) status,are to add value to certain high-quality products obtained from particulars olive varieties cultivated in a specific geographic area. Therefore, the identification of olive genotypes used for Extra Virgin Olive Oil (EVOO) production is essential for the final characteristics of designation oils (PDO, RDO, IGP, etc.,) (Figure 1).

The EEC $n^{\circ} 2081 / 1992$, has defined the relative contribution of specific cultivars for every commercial oil designation. For this reason, it is necessary to develop procedures for cultivar identification, in order to be able to directly demonstrate that the legally mandated cultivar composition has been respected [3].

Although, different types of analysis can be useful to authenticate the EVOOs, conventionally assessed, analysing the content of metabolites such as: fatty acids, triacylglycerol, n-alkanes, volatile compounds and tocopherols [6,7], the characterization of the genetic identity of DNA recoverable from EVOO is the only technique that guarantees the identification of different contributions of olive varieties to the EVOOs mixture, as stated by each Designation Regulation. In addition, the DNA-based technologies are not influenced by environmental conditions and provide an opportunity for direct comparison of different genetic materials reported in the databases. The employment of DNA-based markers in EVOO characterisation offers a number of advantages over biochemically-based markers such as anincreased specificity, sensitivity and a reliable performance with highly processed samples $[1,8]$.

Food genomic relies on the hypothesis that remnant DNA in a food matrix can be recovered to serve as an analyte in food authenticity analyses [1,3]. PCR-based techniques are often essential in order to amplify the residual DNA in a food matrix to useful quantities for downstream analyses, but all genotyping platforms can be utilized in food genomic analyses.

Amplified fragment length polymorphism (AFLP), random amplified polymorphic DNA (RAPD), inter-simple sequence repeats (ISSR), simple sequence repeats (SSR) or microsatellites, and single nucleotide polymorphisms (SNP) have been proposed to identify olive cultivars and for traceability of VOO. At present, SSRs are the most relevant genetic markers used in olive cultivar characterization and EVOO authenticity, thanks to their numerous properties. Indeed, SSR markers are multiallelic, codominant, highly polymorphic, widely distributed along the plant genomes and easily amenable to PCR-based analyses. Moreover, they have great reproducibility and currently, they are the most reliable DNA profiling techniques in forensic investigation [9]. However, SSRs are one of the most useful molecular markers in plant breeding, and they are widely used for olive cultivar fingerprinting [10-15].

The evidence of authenticity of an oil sample claimed to be obtained from a specific cultivar generally should reside in the match between its microsatellite profile and the one of plants (leaves), reported in reference databases. In this context, to efficiently identify and analyse the unknown commercial virgin olive oils, the development of a database, including information about olive cultivars and olive oils based on genetic data sets, particularly, SSR markers, becomes necessary $[3,16]$.

However, the reliability and reproducibility of the profiles obtained by means of molecular markers appear strictly dependent on the quality of the DNA extracted from oil $[3,17]$. Therefore, extraction and recovery of DNA from olive oil is a key and hard step in the process, as addressed by different authors [3,17-20]. Among these oil-based studies, there have been efforts to evaluate the degree of similarity between oil DNA and leaf DNA [3,21-23].

In some publications, authors report discrepancies between the results obtained from versus oils, suggesting differences in the quality of the DNA that is extracted [3] and even going so far as to suggest that the commercial monovarietal olive oils might contain $5-10 \%$ of oil derived from other cultivars [22]. Finally, several reports claimed a relatively high stability of olive oil DNA during storage [24].

The aim of this mini-review is to point out the latest innovations from the scientific world on the main issues of the composition and the authentication of EVOOs by means of molecular markers.

\section{SSR Database of the Olive Germplasm}

Currently, on the basis of estimates from the FAO Olive Germplasm Plant Production and Protection Division, the world olive germplasm contains more than 2.600 different varieties [25], but this data could be underestimated because there is a significant lack of information regarding minor local varieties and ecotypes that are widespread in different olive-growing areas [11,26,27].

To date, exhaustive analyses of olive germplasm cultivated on the main reference collections have been achieved [3]. In this respect, several Mediterranean countries have promoted ex situ olive germplasm collections, including Cordoba (Spain), Marrakech (Morocco), Porquerolles (France), and Cosenza (Italy), which host the majority of olive varieties. These efforts allowed to set up and fill in large molecular databases, which are essential for true-totype cultivar identification, as well as to analyse genetic diversity for further prospecting and for the introduction of new olive cultivars [10-15].

To identify an unknown EVOO, a reference system becomes necessary. However, few online databases have been developed for olive trees (Oleaeuropaea L.), Such as Italian olive database [28], olive genetic diversity database [29], OLEA databases [30] and Istrian olive database [31]. In each database, all SSR molecular profiles of various olive varieties cultivated in their respective 
ex-situ collections are reported. In some databasesit is possible to query for cultivars corresponding to a specific data profile or, on the contrary, to search for the variety identity when a profile is available. To date, the number of SSR profiles described in the database is: 489 in Italian olive database [13], 200 in olive genetic diversity database [11], 80 in OLEA databases [26] and 13 in Istrian olive database [32], although many other databases are not open access.

\section{Recovery of DNA from EVOO}

The first report present on public databases (SCOPUS, Web of knowledge, Pubmed) about the traceability of olive oils by means of molecular markers was Muzzalupo and Perri [33]. Since then many progress has been made, but others are still to be accomplished. In any case very important is the quantity and quality of the residual DNA in the olive oils.

DNA extracted from olive oil can be highly degraded and contaminated with inhibitors of the PCR reaction, which limit the applicability of DNA genetic markers to the traceability of olive oil $[3,22,34]$. This drawback could be overcome by improving the DNA isolation method and by optimizing the amplification system.

In recent years, many papers dealing with the development of new protocols $[17,19,21,35]$ or the comparison of different methods to find an adequate approach $[3,20]$. Scollo [20] applied droplet digital PCR (ddPCR) to quantify the DNA recovered from oil by applying different methods. The authors demonstrated that the methods could modify the quantity/quality of recovered DNA and overall reproducibility. The ddPCR is an endpoint PCR $[20,36]$, enabling the quantification of DNA irrespective of the efficiency of the PCR.The efficiency of the PCR can be influenced by the presence of inhibitors whose presence can result in the lack of reproducibility.

Very recently, the purification of extracted DNA by excision of the less degraded fragments from agarose gel and subsequent electro elution has been proposed, [17], whereas another approach proposed to totally by-pass the DNA extraction step by exploiting a DNA polymerase. In the last case, the DNA polymerase (KAPA3G Plant DNA polymerase, Kapa Biosystems, Inc., Boston, MA, USA) was able to tolerate PCR inhibitors applied directly on crude oil [18]. These latest molecular results may be used to mark the origin for the olive oils produced by these varieties. In addition, by contributing to a better understanding of cultivated olive germplasm relationships, molecular results can provide useful information for cultural purposes, aimed to preserve the cultural and historical heritage, represented by ancient olive trees [37]. The need of further working towards the quantification of varietal composition, by taking advantage of the great potential of HRM and qRT-PCR techniques and the most recent omics technologies, remains in the near future [38,39].

\section{Concluding Remark}

In the olive oil industry, the identification process of EVOO varieties is very interesting with numerous commercial implications. The possibility of providing a market food product with a genetic fingerprint is undoubtedly a benefit, especially if we consider the issue of counterfeit food products around the world. The comparing between the molecular SSR profiles, obtained from the EVOO by using a DNA polymerase able to tolerate PCR inhibitors and the same loci present in an online molecular databases, allows establishing the origin olive varieties and the respect for the disciplinary of production (POD, RDO, PGI, etc.).).In Italy, some laboratories already work on this certification and by computerizing the molecular profiles obtained from the EVOO, can process an "identity card" containing the commercial information and the molecular footprint of the oil. This "identity card" can be inserted into a barcode or QR code or microchips on the labels or bottle caps and it can be consulted by a smartphone.

Furthermore, the experimental procedures described in this mini-review are a strategic and advantageously easy tool, available for his fraud repression sector to speed up checks on fraud and food adulteration and therefore improve consumer protection. These results are also in line with the latest rules issued by the European Union and International Institutions (eg. Nagoya Protocol) aimed to save the genetic resources and other niche products.

\section{References}

1. Agrimonti C, Vietina M, Pafundo S, Marmiroli N (2011) The use of food genomics to ensure the traceability of olive oil. Trends Food Sci Technol 22(5): 237-244.

2. Madesis P, Ganopoulos I, Sakaridis I, Argiriou A, Tsaftaris A, et al. (2014) Advances of DNA-based methods for tracing the botanical origin of food products. Food Res Int 60: 163-172.

3. Pasqualone A, Montemurro C, Di Rienzo V, Summo C, Paradiso V, et al. (2016) Evolution and perspectives of cultivar identification and traceability from tree to oil and table olives by means of DNA markers. J Sci Food Agric 96(11): 3642-3657.

4. Ferreiro GM, Barbero GF, Álvarez JA, Ruiz A, Palma M, et al. (2017) Authentication of virgin olive oil by a novel curve resolution approach combined with visible spectroscopy. Food Chem 220:331-336.

5. Messai H, Farman M, Sarraj LA, Hammami SA, Semmar N, et al. (2016) Chemometrics methods for specificity, authenticity and traceability analysis of olive oils: principles, classifications and applications. Foods 5(4): 77-112.

6. Mihailova A, Abbado D, Kelly SD, Pedentchouk N (2015) The impact of environmental factors on molecular and stable isotope compositions of n-alkanes in Mediterranean extra virgin olive oils. Food Chem 173: 114121.

7. Semmar N, Laroussi MS, Grati KN, Hammami M, Artaud J, et al. (2016) A new simplex chemometric approach to identify olive oil blends with potentially high traceability. Food Chem 208: 150-160.

8. Ramos GS, Busto MD, Albillos SM, Ortega N (2016) Novel qPCR systems for olive (Olea europaea $L$.) authentication in oils and food. Food Chem 194: 447-454.

9. Ben Ayed R, Kamoun GN, Rebai A (2013a) An overview of the authentication of olive tree and oil. Compr Rev Food Sci F 12(2): 218227.

10. Abdessemed S, Muzzalupo I, Benbouza H (2015) Assessment of genetic diversity among Algerian olive (Oleaeuropaea L.) cultivars using SSR markers. Scientia Horticulturae 192: 10-20. 
11. Ben Ayed R, Ben Hassen H, Ennouri K, Ben Marzoug R, Rebai A, et al (2013b) OGDD (Olive Genetic Diversity Database): a microsatellite markers' genotypes database of worldwide olive trees for cultivar identification and virgin olive oil traceability. Database bav090.

12. Mousavi S, Mariotti R, Regni L, Nasini L, Bufacchi M, et al. (2017) The first molecular identification of an olive collection applying standard Simple Sequence Repeats and novel expressed sequence Tag markers. Front Plant Sci 8: 1283

13. Muzzalupo I, Vendramin GG, Chiappetta A (2014) Genetic biodiversity of Italian olives (Olea europaea) germplasm analyzed by SSR markers. Sci World J 2014: 296590.

14. Sakar E, Unver H, Ercisli S (2016) Genetic diversity among historical olive (Olea europaea L.) genotypes from Southern Anatolia based on SSR markers. Biochem Genet 54(6): 842-853. al. (2016) New accessions of Italian table olives (Olea europaea): characterization of genotypes and quality of brined products. Sci Hortic 213: 34-41.

16. Sebastiani L, Busconi M (2017) Recent developments in olive (Olea europaea $L$.) genetics and genomics: applications in taxonomy, varietal identification, traceability and breeding. Plant Cell Rep 36(9): 13451360.

17. Raieta K, Muccillo L, Colantuoni V (2015) A novel reliable method of DNA extraction from olive oil suitable for molecular traceability. Food Chem 172: 596-602.

18. Muzzalupo I, Pisani F, Greco F, Chiappetta A (2015) Direct amplification of the virgin olive oil for the traceability and authenticity. Eur Food Res Technol 241(1): 151-155.

19. Ramos GS, Busto MD, Perez MM, Ortega N (2014) Development of a method to recovery and amplification DNA by real-time PCR from commercial vegetable oils. Food Chem 158: 374-383.

20. Scollo F, Egea LA, Gentile A, La Malfa S, Dorado G, et al. (2016) Absolute quantification of olive oil DNA by droplet digital-PCR (ddPCR): comparison of isolation and amplification methodologies. Food Chem 213: 388-394.

21. Alonso RA, Ramos GS, Busto MD, Ortega N (2017) Development and optimization of an efficient qPCR system for olive authentication in edible oils. Food Chem 232: 827-835.

22. Doveri S, O’Sullivan DM, Lee D (2006) Non-concordance between genetic profiles of olive oil and fruit: a cautionary note to the use of DNA markers for provenance testing. J Agric Food Chem 54(24): 9221-9226.

23. Muzzalupo I, Pellegrino M, Perri E (2007) Detection of DNA in virgin olive oils extracted from destoned fruits. Eur Food Res Technol 224(4): 469-475.
15. Sorrentino G, Muzzalupo I, Muccilli S, Timpanaro N, Russo MP, et

24. Spaniolas S, Bazakos C, Ntourou T, Bihmidine S, Georgousakis A, et al. (2008) Use of lambda DNA as a marker to assess DNA stability in olive oil during storage. Eur Food Res Technol 227(1): 175-179.

25. FAO (2010) The second report on the state of the world's plant genetic resources for food and agriculture. Rome, Italy.

26. Bartolini (2008) Olea databases.

27. Muzzalupo I, Perri E, Chiappetta A (2012) Chapter 4- Fruit germplasm characterization: genomics approaches for the valorisation of genetic diversity. In: Çalişkan M (Ed.), Genetic diversity in plants. In Tech, Rijeka, Croatia, pp. 55-86.

28. http://www.certolio.org/database-varietale/

29. http://www.bioinfo-cbs.org/ogdd/

30. http://www.oleadb.it/

31.http://www.iptpo.hr/iod/

32. Poljuha D, Sladonja B, Šetiæ E, Milotiæ A, Bandelj D, et al. (2008) DNA fingerprinting of olive varieties in Istria (Croatia) by microsatellite markers. Sci Hortic 115(3): 223-230.

33. Muzzalupo I, Perri E (2002) Recovery and characterization of DNA from virgin olive oil. Eur Food Res Technol 214: 528-531.

34. Montemurro C, Miazzi MM, Pasqualone A, Fanelli V, Sabetta W, et al. (2015) Traceability of PDO olive oil 'Terra di Bari' using high resolution melting. J Chem 2015: 496986

35. Uncu AT, Uncu AO, Frary A, Doganlar S (2017) Barcode DNA length polymorphisms vs fatty acid profiling for adulteration detection in olive oil. Food Chem 221: 1026-1033.

36. Pinheiro LB, Coleman VA, Hindson CM, Herrmann J, Hindson BJ, et al. (2012) Evaluation of a droplet digital polymerase chain reaction format for DNA copy number quantification. Anal Chem 84(2): 1003-1011.

37. Chiappetta A, Muto A, Muzzalupo R, Muzzalupo I (2017) New rapid procedure for genetic characterization of Italian wild olive (Olea europaea) and traceability of virgin olive oils by means of SSR markers. Sci Hortic 226: 42-49.

38. Chiappetta A, Bruno L, Muzzalupo I (2015) Chapter 2- Omics approaches for the characterization and valorisation of olive varieties. In: Muzzalupo, Micali (Eds.), Agricultural and food biotechnologies of Oleaeuropaea and stone fruit. Bentham Science Publishers LTD., Sharjah, UAE, pp. 75-108.

39. Pasqualone A, Alba V, Mangini G, Blanco A, Montemurro C, et al. (2010) Durum wheat cultivar traceability in PDO Altamura bread by analysis of DNA microsatellites. Eur Food Res Technol 230(5): 723-729.

\section{Your subsequent submission with Crimson Publishers will attain the below benefits}

Creative Commons Attribution 4.0

International License

For possible submissions click Here

$$
\text { Submit Article }
$$

